\title{
Impact of Parents psychiatric disorders on the evolution of children Autism spectrum disorder
}

\author{
Nabli,R, Brahim,T, Gaddour N \\ UNIVERSITY OF MONASTIR-TUNISIA
}

\section{Introduction}

Having a parent with a psychiatric disorder have an impact on the well being and the development of the child. Is there an influence on the evolution of the Autism spectrum disorder (ASD) by this fact?

\section{Aim}

To Determine the relation between parents' history of psychiatric disorder and the evolution of the severity of the ASD

\section{Methods}

Type: Retrospective study

Population: Children diagnosed with ASD, who have been followed for at least 3 years, in the outpatient unit of child psychiatry. We recruited 287 Children with ASD

Location and Period: In the outpatient unit of Child Psychiatry, University hospital of Monastir, Tunisia; from 2010 to 2012.

Tools: Childhood Autism Rating Scale: Severity Evaluation of the ASD

Psychiatric interview, DSM-5 criteria: ASD diagnosis

\section{Results}

\begin{tabular}{|l|l|}
\hline Average Age at Diagnosis & $3.88 \pm 2.79$ \\
\hline Sex Ratio & 3.9 \\
\hline Mother's Average Age at Diagnosis & $30.52 \pm 5.70$ \\
\hline Father's Average Age At Diagnsosi & $36.58 \pm 6.59$ \\
\hline CARS First Evaluation & $37.92 \pm 7.54$ \\
\hline CARS Last Evaluation & $25.85 \pm 13.49$ \\
\hline
\end{tabular}

\section{Q Population Caracteristics}

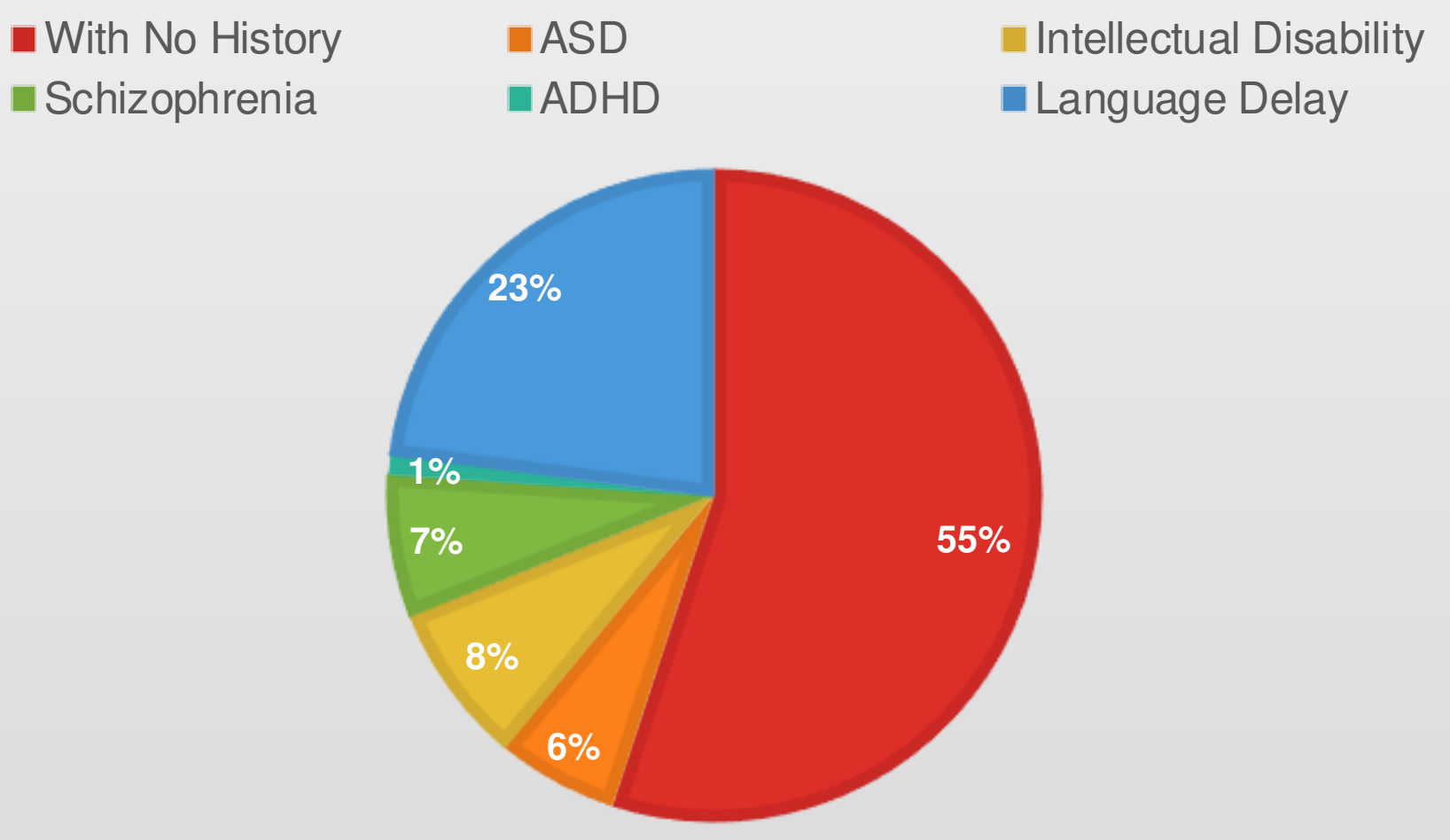

Parent's History of psychiatric disorders

\begin{tabular}{llll|} 
& $\begin{array}{l}\text { With Parent's } \\
\text { History }\end{array}$ & $\begin{array}{l}\text { Without Parent's } \\
\text { History }\end{array}$ & $\mathbf{p}$ \\
\hline $\begin{array}{l}\text { CARS First } \\
\text { Evaluation }\end{array}$ & $37.34 \pm 7.82$ & $38.79 \pm 8.09$ & .442 \\
$\begin{array}{l}\text { CARS Last } \\
\text { Evaluation }\end{array}$ & $30 \pm 8.34$ & $31.37 \pm 8.87$ & .633 \\
\hline
\end{tabular}

Relationship between Parent's History and CARS evolution

\section{Conclusions}

We did not found any correlation between having a praents with a history of psychiatric disorders and the severity of ASD at the first evaluation, nor with the evolution after intervention. However, this study suffer many biases, principally the very size of our simple. We need to preceed further investigations to make conclusion. 